\title{
IL-1 Receptor Antagonist Production by Isolated Mononuclear Cells Is a Better Indicator of Bioincompatibility of Hemodialysis Membranes than That by Stimulated Whole Blood
}

\author{
$\begin{array}{llll}\text { E. Tuma }^{a} & \text { A. Eigler } & \text { M. Toepfer } & \text { S. Endres } \\ & \text { a } & \text { H. Schiff } & \text { b }\end{array}$ \\ Departments of aClinical Pharmacology, and ${ }^{b}$ Nephrology, Medizinische Klinik Innenstadt, \\ Klinikum der Universität, Munich, Germany
}

Dear Sir,

Compelling evidence has accumulated that monocyte-derived cytokines, particularly the interleukin (IL) 1 family, play a pathogenetic role in acute (fever, hypotension) and long-term complications of hemodialysis (susceptibility to infections, atherosclerosis, and amyloidosis). IL-1 $\alpha$ and IL-1 $\beta$ are potent proinflammatory mediators. The IL-1 receptor antagonist (RA) is concurrently released with IL-1. The IL-1 RA is a specific inhibitor and acts by binding to IL-1 cell surface receptors without triggering a biological response. A number of studies reported elevated (3- to 5-fold) plasma IL-1 RA levels and increased cellular IL-1 RA production in dialysis patients [1,2]. It is presently unknown whether the IL-1 RA production changes with modifications of the dialysis membrane or alterations of the quality of the dialysate. Studies reported either unchanged [3, 4], decreased [5], or increased [6] IL-1 RA production and plasma levels during hemodialysis sessions. The discrepancy between these data may be related to both methodological and biological differences among the patients participating in these studies.

The aim of the present study was to compare the effects of membranes differing in their potential to activate complement and monocytes on dialysis-induced changes in

This work was part of the inaugural dissertation performed by E. Tuma. the cytokine production by monocytes and to assess which parameters of IL-1 RA production (cellular release after endotoxin stimulation by peripheral blood mononuclear cells or by whole blood) are better surrogate markers for dialysis membrane bioincompatibility. As plasma values correlate best with residual renal function and clearance in hemodialysis patients and not with the activation of mononuclear cells, the ex vivo production by mononuclear cell appears to be a better method to study IL-1 RA as a marker of activation [7].

Six stable dialysis patients (4 men and 2 women, age range 40-72 years) participated in a crossover comparison of a biocompatible high-flux synthetic membrane (Arylane 4, polyarylether sulfone, surface area $1.35 \mathrm{~m}^{2}$; Hospal, Meyzières, France) and a bioincompatible low-flux cellulosic membrane (Disscap 150, cuprophane, surface area $1.3 \mathrm{~m}^{2}$; Hospal).

They had received hemodialysis for an average of 55 (range 13-81) months. The patients' treatment sessions lasted $4 \mathrm{~h}$ three times per week. Dialysis was performed with dialysis fluid produced by reverse osmosis (mean number of colony-forming units 20/ $\mathrm{ml}$, range $0-40 \mathrm{ml}$ ) mixed with commercial bicarbonate and acid concentrates by proportioning systems. Ultrafiltration was volumetrically controlled (MTS 4008; Fresenius, Oberursel, Germany). Vascular access to the extracorporeal circulation was via fistulae. The cause of end-stage renal disease was chronic glomerulonephritis in 2 patients, hypertensive nephroangiosclerosis in 2 patients, and polycystic kidney disease or Balkan nephritis in 1 patient each. None of the patients had an acute infection, a chronic inflammatory disorder, or malignancy. They all received recombinant human erythropoietin to achieve hemoglobin target levels of $10-11 \mathrm{~g} / \mathrm{dl}$. Blood samples for the determination of circulating leukocytes, complement compound C5a (Behringwerke, Marburg, Germany), and IL-1 RA production (R\&D Systems, Minneapolis, Minn., USA) after endotoxin stimulation $(10 \mathrm{ng} / \mathrm{ml})$ of mononuclear cells or whole blood were taken at the start of the dialysis session, $20 \mathrm{~min}$ after initiation of dialysis, and at the end of the dialysis session. Data for each of these time points are shown in table 1.

During the early phase of cuprophane dialysis, there was a rapid and pronounced drop in circulating white blood cell count caused by a drop in neutrophils and monocytes. At the end of cuprophane dialysis, there was a slight overshoot of the white blood cell count. By contrast, the synthetic membrane caused only a slight, but statistically not significant change in white blood cell count. Cuprophane membranes induced a sharp rise of complement compound C5a after $20 \mathrm{~min}$ which decreased towards the end of treatment, but did not normalize. The use of the polyarylether sulfone membrane was associated with a slight increase in this compound, resulting from activation of the

\section{KARGER \\ Fax +4161306 1234 E-Mail karger@karger.ch} www. karger.com (c) 2000 S. Karger AG, Basel

0028-2766/00/0862-0220\$17.50/0

Accessible online at: www. karger.com/journals/nef
Prof. H. Schiffl

Department of Nephrology, Medizinische Klinik Innenstadt, Klinikum der Universität Ziemssenstrasse 1

D-80336 Munich (Germany)

Tel. +49 8951602364 , Fax +49 8951604576 
Table 1. Changes in white blood cell count, complement C5a, and IL-1 RA release during hemodialysis using membranes with different biocompatibility (mean \pm SEM)

\begin{tabular}{|c|c|c|c|c|c|c|}
\hline & \multicolumn{6}{|l|}{ Membrane } \\
\hline & \multicolumn{3}{|l|}{ cuprophane } & \multicolumn{3}{|l|}{ Arylane } \\
\hline & $0 \mathrm{~min}$ & $20 \mathrm{~min}$ & $240 \mathrm{~min}$ & $0 \mathrm{~min}$ & $20 \mathrm{~min}$ & $240 \mathrm{~min}$ \\
\hline White blood cell count, $\times 1,000 / \mu 1$ & $6.7 \pm 0.5$ & $2.2 \pm 0.2 *$ & $7.2 \pm 1.1$ & $6.8 \pm 0.4$ & $6.5 \pm 0.8$ & $5.7 \pm 0.7$ \\
\hline Complement C5a, ng/ml & $0.62 \pm 0.08$ & $15.34 \pm 3.14^{*}$ & $3.14 \pm 0.51$ & $0.52 \pm 0.07$ & $0.77 \pm 0.14$ & $0.98 \pm 0.23$ \\
\hline \multicolumn{7}{|l|}{ IL-1 RA, pg/ml } \\
\hline Whole blood & $20,658 \pm 4,223$ & $1,246 \pm 173$ & $16,043 \pm 2,059$ & $24,698 \pm 4,150$ & $11,371 \pm 5,056$ & $17,610 \pm 4,028$ \\
\hline Mononuclear cells & $46,901 \pm 5,854$ & $19,978 \pm 6,504$ & $66,143 \pm 4,624^{*}$ & $49,860 \pm 12,871$ & $41,493 \pm 9,713$ & $38,552 \pm 8.765$ \\
\hline
\end{tabular}

$* \mathrm{p}<0.01$ versus corresponding parameters.

alternate pathway of the complement system. While both membranes did not significantly alter IL-1 RA production in whole blood, the use of the cuprophane membrane induced a significant rise in the cellular production of IL-1 RA by mononuclear cells.

Our study using dialyzer membranes with different capability to induce complement and cell activation, in conjunction with low levels of dialysis fluid contamination, demonstrated a significant increase of cellular IL-1 RA release during clinical hemodialysis with new cuprophane membranes. These data support the widely accepted hypothesis of a complement- or membraneinduced transcriptional signal, followed by endotoxin-induced translational stimulus in bicarbonate dialysis fluid.

The notion of dialysis-induced increases in cellular IL-1 RA production using cellulosic but not synthetic membranes is largely in agreement with two other observations. The first is that new and reused cuprophane membranes were associated with raised IL-1 RA production during the early phase of the dialysis session (drop in cellular production at time point $20 \mathrm{~min}$ ) [8]. The second is that cellulosic membranes caused a significant and polysulfone only a mild change at the end of dialysis [6]. This dialysis-induced increase demonstrates the bioincompatibility of cuprophane membranes and conversely shows the biocompatibility of polyarylether sulfone membranes.

Discrepancies between other studies may be explained by different methods used as well as by differences in patients studied (nutritional status, erythropoietin, presence of infections or inflammation). All previous studies failed to detect significant changes in plasma IL-1 RA concentrations. Therefore, the whole-blood stimulation system could have been an alternative surrogate marker for hemodialysis bioincompatibility, since it does not require an isolation procedure. The present study demonstrates that determination of mononuclear cell released IL-1 RA still represents a better indicator of the host response to cytokine stimuli encountered during bioincompatible hemodialysis than determination of IL-1 RA production in stimulated whole blood.

The high IL-1 RA levels appear to be mostly an expression of the inflammatory state which hemodialysis resembles rather than to have a pathogenetic role. In fact, it has been shown that as much as a 100 -fold to 1,000-fold excess of IL-1 RA concentration and not a 3- to 5-fold increase in predialysis or postdialysis levels, respectively, is required to inhibit IL-1-induced responses in T lymphocytes and other target cells [9].

The cellular production of IL-1 RA is a sensitive marker of membrane- and dialysate-induced mononuclear cell stimulation and may serve as a new surrogate marker for the total hemodialysis procedure. Long-term clinical studies will have to show whether this marker correlates with clinical manifestations of cytokine release such as premature development of atherosclerosis or amyloidosis.

\section{References}

1 Balakrishnan VS, Jaber BL, Natov SN, Cendoroglo M, King AJ, Schmid CH, Pereira BJG: Interleukin-1 receptor antagonist synthesis by peripheral blood mononuclear cells in hemodialysis patients. Kidney Int 1998;54:2106-2112.
2 Pereira BJ, King AJ, Falagas ME, Dinarello CA: Interleukin-1 receptor antagonist: An index of dialysis-induced interleukin-1 production. Nephron 1994;67:358-361.

3 Grooteman MP, Nube MJ, Daha MR, Van Limbeek J, van Deuren M, Schoorl M, Bet PM, Van Houte AJ: Cytokine profiles during clinical high-flux dialysis: No evidence for cytokine generation by circulating monocytes. J Am Soc Nephrol 1997;8:1745-1754.

4 Frith SE, Hoenich NA, Redfern CP, Goodship TH: Production of interleukin 1 receptor antagonist and interleukin 1 during haemodialysis with cellulose membranes. Int J Artif Organs 1994; 17:478-487.

5 Descamps-Latscha B, Herbelin A, Nguyen AT, Roux-Lombard P, Zingraff J, Moynot A, Verger C, Dahmane D, de Grootes D, Jungers $\mathrm{P}$, et al: Balance between IL- 1 beta, TNF- $\alpha$, and their specific inhibitors in chronic renal failure and maintenance dialysis: Relationships with activation markers of $T$ cells, $B$ cells, and monocytes. J Immunol 1995; 154:882-892.

6 Donati D, Degiannis D, Mazzola E, Gastaldi L, Raskova J, Raska KJ, Camussi G: Interleukin-1 receptors and receptor antagonist in haemodialysis. Nephrol Dial Transplant 1997;12: 111-118.

7 Dinarello CA: Interleukin-1 and interleukin-1 receptor antagonist production during haemodialysis: Which cytokine is a surrogate marker for dialysis-related complications? Nephrol Dial Transplant 1995;10(suppl 3):25-28.

8 Pereira BJ, King AJ, Poutsiaka DD, Strom JA, Dinarello CA: Comparison of first use and reuse of Cuprophan membranes on interleukin-1 receptor antagonist and interleukin-1 $\beta$ production by blood mononuclear cells. Am J Kidney Dis 1993;22:288-295.

9 Pereira BJ: Cytokine production in patients on dialysis. Blood Purif 1995;13:135-146. 